\title{
"HEIDEGGER", EN AUTOBIOGRAFÍA FILOSÓFICA DE KARL JASPERS
}

RESUMEN: En estas páginas, el lector encontrará por vez primera en castellano la versión íntegra del capítulo que Karl Jaspers, en su Autobiografia filosófica, dedicó a su colega y “amigo" Martin Heidegger. Jaspers relata los sucesos que ocurrieron entre ambos durante cerca de trece años y que concluyen con el fracaso de su amistad; por otro lado, Jaspers intenta tematizar las condiciones sobre las que es posible una crítica filosófica entre contemporáneos.

yose

ABSTRACT: In this article, the reader will find for the first time in Spanish the complete version of Karl Jaspers' chapter of his Philosophical Autobiography, which is dedicated to his colleague and "friend" Martin Heidegger. In it, he recounts their friendship of thirteen years and its end. In addition, Jasper attempts to categorize the necessary conditions for a philosophical criticism between contemporaries.

PALABRAS ClAVE: Karl Jaspers, Autobiografía filosófica, Martin Heidegger, nacionalsocialismo alemán, crítica filosófica.

KEY WORDS: Karl Jaspers, Philosophical Autobiography, Martin Heidegger, German national socialism, philosophical criticism.

RECEPCIÓN: 20 de enero de 2014.

APROBACIÓN: 25 de febrero de 2014. 
CITAM Derechos Reservados.

La reproducción total o parcial de este artículo se podrá hacer si el ITAM otorga la autorización previamente por escrito. 


\title{
"HEIDEGGER", EN AUTOBIOGRAFÍA FILOSÓFICA DE KARL JASPERS
}

\section{Historia de unas páginas desprendidas}

\begin{abstract}
Alrededor de los años 50 del siglo pasado, el profesor Paul Artuhr Schilpp - quien, entre otras cosas, impartió en sus últimos años de vida cursos de filosofía para licenciados en la Universidad sureña de Illinois, y también se encargó de la biblioteca de filósofos vivientes- solicitó a Karl Jaspers que relatara las circunstancias que le llevaron a adentrarse en el camino de la filosofía. Para el año de 1957, gracias al profesor Schilpp, siendo Jaspers ya catedrático en la Universidad de Basilea, se publicó su texto Autobiografía filosófica, en un libro llamado The Philosophy of Karl Jaspers (New York, Tudor Publishing House, 1957). Este volumen presenta lo que podemos llamar el itinerario de la vida intelectual de Karl Jaspers, el cual es expuesto de un modo peculiar, en tanto que dicho itinerario está relacionado con personas y no sólo con temas, como es el capítulo que dedica al filósofo Heinrich Rickert, o aquel otro dedicado a su colega médico y amigo Ernst Mayer, hermano de su esposa Gertrud Mayer. Digno de destacar es, así, que la vida de un filósofo no sólo está motivada por asuntos o problemas, sino que también -quizás más intensamente, aunque no siempre de un modo consciente- por personas con las cuales comparte una, como diría Jaspers, comunidad de destino.

En la versión de la Philosophische Autobiographie publicada en 1957 en alemán (Kohlhammer, Stuttgart, 1957), Jaspers no incluyó una sola
\end{abstract}


palabra de quien indudablemente fue la persona que mayor conmoción provocó en su labor filosófica; nos referimos a Martin Heidegger. Los auténticos motivos del silencio de Jaspers frente a Heidegger en el ámbito público sólo serían revelados posteriormente. Por su lado, A. M. Olson -quien fue director de la Karl Jaspers Society of North America, y que es coeditor del periódico en línea Existenz-destaca que Jaspers expresó subrepticiamente sus opiniones sobre Heidegger en otros trabajos; así, por ejemplo, en Jesús. La desmitologización del nuevo testamento, en donde sostiene una disputa con el teólogo evangélico Rudolf Bultmann, quien recurre en su pensamiento a la analítica existencial de Heidegger. El propio Jaspers reconoce en las Notizen zu Martin Heidegger (München, Piper \& Co. Verlag, 1978), en aquellas que corresponden a los años 1954-1955, que expresó su rivalidad y su crítica en algunos escritos, aunque advierte que tales expresiones nunca tocan el fondo de la rivalidad esencial y real.

En todo caso, es inmediatamente visible en las Notizen -que fueron las notas personales, redactadas desde 1928, halladas a su muerte en el escritorio de Jaspers, y que serían publicadas de manera póstumael dolor que Jaspers experimentó ante el fracaso de su amistad con Heidegger. Ese dolor, tiempo después del rompimiento de 1933, 1levó a Jaspers a intensificar la atención en el trabajo de quien lo instó a establecer una comunidad de lucha. Quizás esa atención continua, llevada a cabo sobre todo en notas personales, haya sido su intento de encontrar un camino para la reconciliación, a la cual nunca estuvo cerrado, pero que igualmente presentaba un grado de exigencia difícil de comprender y aceptar, aun observándolo desde fuera. El camino de las Notizen no era todavía el de una crítica, sino sólo anotaciones pensadas con vistas a un cuestionamiento posible.

Más allá de las inclinaciones que se sientan ante las obras de Heidegger o Jaspers, no cabe hacer un juicio fundado sobre quién haya sido culpable de su rompimiento, ni mucho menos cabe especular si su conflicto se debía a una especie de excesiva egolatría filosófica. Incluso cuando hay gente que hoy en día se empeña en mostrar la "obsesión” de Jaspers por Heidegger con métodos meramente interpretativos, debemos mencionar 
que esto sólo acaba por llevar la atención hacia el terreno de la conjetura y la habladuría, con lo cual se aniquila toda reflexión seria sobre las observaciones que los pensadores se hacían, de manera expresa o implícita. Más aún: frente a esa aparente obsesión unilateral, cabe destacar que en una carta del $1^{\circ}$ de julio de 1935 -esto es, pasados ya más de 10 años de amistad, y después del distanciamiento de 1933Heidegger confiesa a Jaspers tener en su mesa de trabajo una carpeta con el título Jaspers, en la cual cada día entraba una hoja de anotaciones al tomo tercero de su obra Filosofía, el cual tiene como meta aclarar la posibilidad y sentido de la metafísica. No por morbo, sino por su relevancia filosófica, sería fructífero saber si existe aún, o existió, tal carpeta y revisar su contenido. Sólo con los textos de autoría propia, con referencias explícitas y no con conjeturas, cabría comenzar a hacer una confrontación objetiva, y solamente objetiva, entre ambos pensadores.

Así, lo único constatable hasta ahora del rompimiento por parte de Jaspers es su rechazo a Heidegger después de que éste manifestara cierta simpatía por Hitler y el nacionalsocialismo en 1933 -aunque dicha simpatía, como se deja ver en la entrevista que dio Heidegger para Der Spiegel, no estuvo fundada en un asentimiento ideológico, sino en la creencia errónea de que se trataba de una vía para el resurgimiento del espíritu de la Universidad. En tal manifestación, Jaspers vio encarnados todos los fantasmas que le impulsaban hacia un rechazo, pero no sólo de la obra de Heidegger, sino de su persona. Para Jaspers tampoco careció de relevancia el silencio que guardó Heidegger ante su destitución de la Universidad de Heidelberg en 1937. He aquí lo que parece sugerir una posterior 'venganza' del pensador de la existencia frente al pensador de la historia del ser en el proceso de desnazificación de la Universidad. Este rechazo, aunado a la creciente atención de Jaspers en la actividad íntegra de Heidegger, y considerando al menos la posibilidad de que el silencio de Heidegger en 1937 haya afectado aún más su estima, desembocaría presumiblemente en el muy controversial contenido de la carta de referencia que solicitó Friedrich Oehlkers -miembro de la comisión depuradora del profesorado de la Universidad de Friburgo-a Jaspers en el año de 1945, en la cual éste sugería la prohi- 
bición temporal a Heidegger para la impartición de lecciones y seminarios. No es de extrañar que Heidegger sintiera una profunda enemistad, una traición, por el juicio de Jaspers, quien había indicado que sólo se le hiciera mención de algunas partes de la carta; con ello, la distancia entre ambos se hizo casi abismal. Sólo quedaron cartas con observaciones mutuas sobre sus trabajos y la esperanza de que, a partir de eso, se barruntara un camino para un reencuentro.

El silencio público ante Heidegger por parte de Jaspers culminó, paradójicamente, con su muerte. En tanto que su esposa y amigos le habían desaconsejado hablar de Heidegger en vida, a su deceso llegó el momento de hacer públicas las Notas -no sabemos si Jaspers deseó hacerlas públicas en el estado en que las dejó- y también el capítulo que en los años 50 había escrito sobre Heidegger para su Autobiografía. Esto quiere decir que Jaspers sí tuvo la intención, en vida, de manifestarse directa y públicamente sobre Heidegger, pero fue persuadido por esposa y amigos de que no lo hiciera. Lo decisivo para la reedición del texto alemán fue que, de hecho, estaba marcado en el manuscrito el lugar que ocupaba el capítulo dedicado a Heidegger. Para los revisores de la obra de Jaspers esto significaba un vacío en tanto que, como dijimos, a

74 pesar del peso que tuvo para su existencia filosófica, y tomando en cuenta la intención original del autor, no se hacía mención de Heidegger en el resto de la Autobiographie. De ahí que en la nueva edición de 1977, apareciera publicada la Philosophische Autobiographie ampliada, con la inclusión entre las páginas 92-111 del capítulo 10, que lleva como título "Heidegger".

Esta versión - publicada por Piper \& Co. Verlag- sólo ha sido traducida íntegramente al inglés; aparece en la reedición del texto de Paul Arthur Schilpp, llamado The Philosophy of Karl Jaspers (Open Court Publishing Company, Illinois, 1981). Las traducciones al francés y al italiano se apegan a la edición de 1958, en tanto que fueron realizadas antes de la publicación de la edición aumentada en alemán. En este mismo caso está la traducción al castellano de la Autobiografía, realizada por Pablo Simón y publicada en 1964 (Editorial Sur, Buenos Aires). 
Es comprensible, en virtud de lo ya dicho, que en aquel entonces no se tuviera conocimiento de tal capítulo en el habla hispana.

Con esto no queremos decir que no se haya dado en nuestra lengua alguna revisión de la versión de 1977 de la Autobiographie; pero no hay evidencia pública de ello más allá de citas aisladas, consignadas con otros fines. Así, en la traducción realizada por Juan José García Norro de la Martin Heidegger/Karl Jaspers. Briefwechsel 1920-1963, se puede ver que en el aparato crítico de la correspondencia -que fue procurado en el original alemán por Walter Biemel y Hans Saner- aparecen algunos fragmentos del capítulo Heidegger. Esto sólo es consecuencia de la traducción del volumen entero de la Correspondencia y no una intención directa sobre el texto de Jaspers.

De este modo, lo significativo para nuestra propuesta de traducción del capítulo es que en esos fragmentos sólo encontramos alusión a los sucesos personales que Jaspers narra; a partir de la lectura de la Correspondencia, el lector de habla hispana no tiene la más mínima noticia del problema estrictamente filosófico que el profesor de Basilea desea poner sobre la mesa: la crítica filosófica entre existencias que comparten una comunidad de destino. El motivo principal para presentar una traducción íntegra al castellano del capítulo es esta falta de noticia acerca de la motivación filosófica que impulsó a Jaspers a dar ese espacio a Heidegger en su Autobiografía. Aunado a esto, el hecho de que en nuestra lengua se tenga noticia únicamente de fragmentos de eso que llamamos la primera parte del capítulo, hace necesaria la accesibilidad a la totalidad del texto a fin de tenerlo en una visión de conjunto. Finalmente, no podemos dejar de reconocer que al presentar el capítulo entero - echando mano de lo polémico de su contenido- tenemos la esperanza de que ello pueda ser un pretexto para volver la mirada hacia el pensamiento de Karl Jaspers, quien sorprendentemente ha sido relegado, bien porque fue devorado por el desánimo que se experimentó después de la Segunda guerra mundial ante aquellos pensadores denominados teístas, bien porque se le ha pensado y conocido siempre a la sombra del complejo pensamiento de Martin Heidegger. Por más que 
el capítulo esté consagrado al desarrollo de su relación con Heidegger, Jaspers no deja de lado la oportunidad de indicar hacia tópicos fundamentales de su camino de pensamiento como es el mundo de los poderes, la comunicación filosófica, la relación entre la reflexión y la praxis, entre otros.

Cabe señalar que nuestra intención no es la de ofrecer elementos para la aclaración de la tormentosa relación entre Jaspers y Heidegger. Insistimos que no se obtiene provecho alguno, al menos no provecho filosófico, de saber si uno provocó despecho y resentimiento al otro. Tampoco buscamos que, a partir de lo dicho por Jaspers sobre la relación de Heidegger y el nazismo, se tomen elementos para un juicio en torno al error político de Heidegger en 1933. No se debe perder de vista que la opinión de Jaspers está realizada desde el fracaso de una amistad, lo cual a su vez armoniza con la no intención de dar un juicio moral público sobre el amigo. Si hemos entendido bien la intención de Jaspers en este pasaje de su Autobiografía, su intento fue el de llevar al nivel de la reflexión lo que experimentó de manera íntima a partir de su fracaso con Heidegger, con lo cual bosquejó apenas los elementos que podrían constituir una crítica existencial frente a un contemporáneo. De lo que no debe caber duda es que Jaspers jamás llevó a cabo tal crítica, bajo sus propios términos; su reencuentro en persona con Heidegger era la condición necesaria y esto nunca sucedió.

Así, el rendimiento de nuestro trabajo puede radicar en que se haga accesible una perspectiva para aclarar el sentido de una crítica filosófica entre pensadores vivos, entre individuos que pueden preguntar y responder mientras respiran un mismo ambiente espiritual. De ahí se hace comprensible que la traducción que presentamos no esté pensada para un público especializado, sea en la obra de Heidegger o en la de Jaspers. Pero no sólo no buscamos dirigirnos a los especialistas, sino que en nuestra traducción buscamos corresponder al modo en que Jaspers expresa su pensamiento. Resulta llamativo que, aun cuando hay un uso peculiar de las palabras, Jaspers buscaba incidir en la conciencia del lector, fuese quien fuese. No pocas veces se le hizo el reproche, un tanto superficial, de carecer de una terminología técnica. Pero creemos 
que no erramos al decir que, para Jaspers, las palabras son siempre una indicación, una seña; más aún, una cifra de la trascendencia. La filosofía era para Jaspers una posibilidad de todo hombre. De ahí que lo primero sea, para nuestro autor, la comunicabilidad del pensamiento, y después la experiencia que produce en nosotros lo comunicado en nuestra existencia posible, en nuestra libertad. En esto segundo estamos en soledad con nuestra reflexión ante lo dicho. Qué repercusión filosófica tenga lo dicho en este capítulo sobre la crítica filosófica, depende únicamente de la ejecución y el alcance que se le dé a lo aquí sugerido.

Por último, es pertinente destacar que la traducción que presentamos es un esfuerzo que he llevado a cabo en conjunto con mi ex-alumna Karla D. González Esquinca, estudiante de la Licenciatura en Relaciones Internacionales del ITAM. A ella agradezco sus profundos conocimientos del alemán, e igualmente su exigencia de naturalidad en el lenguaje castellano. No han sido pocas sus sugerencias; todas ellas han contribuido decisivamente a que el texto gane en claridad y fluidez.

Luis Fernando Mendoza. 


\section{HEIDEGGER}

Lo que escuché de Heidegger al final de la Primera guerra mundial me permitía esperar a un filósofo originario entre los académicos. Él era siete años más joven que yo, profesor no numerario, asistente de Husserl, públicamente apenas conocido, y sin embargo, creador de fama alrededor de él. Yo había dado un paso en el ámbito público gracias a mi Psicopatología, y mi Psicología de las concepciones del mundo. Busqué una relación con él.

Nuestro encuentro fue para Heidegger una sorpresa, para mí una estímulo. La manifiesta conmoción filosófica del discípulo causó impresión en mí. Él había fundado su ocupación filosófica por medio de una decisión del estilo de las más grandes resoluciones del hombre, las que están dispuestas para el riesgo y el sacrificio en la elección de su camino de vida. En el gremio de los filósofos era Heidegger el único que, entre los contemporáneos, me importaba esencialmente. Y así es todavía hoy. Con muchos otros tengo buenas relaciones, aprendo de ellos, tengo estima por su trabajo, pero sin que ellos, en tanto que filósofos, digan o hagan algo que por sí fuese en adición a la filosofía. Heidegger logró mostrar lo más oculto en las conexiones de las preguntas.

En la primavera de 1920 estuvimos mi mujer y yo un único día en Friburgo, con la oportunidad de conversar con Heidegger y Husserl. Se festejaba el cumpleaños de Husserl. La gente se sentó en un gran círculo en la mesa del café. Al mismo tiempo, Heidegger fue nombrado por la esposa de Husserl como el 'niño fenomenológico'. Comenté que una alumna mía, Afra Geiger, una personalidad de primer rango, debía venir a Friburgo para estudiar con Husserl. Según el reglamento de admisión a su seminario, él la rechazó. Así pues, ambos perdieron una buena posibilidad debido al esquematismo académico, porque con ello Husserl omitió la oportunidad para ver a la persona misma. Heidegger intervino vivamente asintiendo conmigo. Era como una solidaridad de los dos discípulos contra las reglas abstractas de la autoridad. El discurso de Husserl era despreocupado. Ya no percibí más la vanidad que 
penosamente me había afectado en Gotinga, en 1913. Él habló sobre las cosas filosóficas, las que le eran esenciales: éstas -opinó amistosamente, sin desprecio ni agravio- serían poco interesantes para mí. Preguntó por mis diversos esfuerzos. Heidegger estaba de ánimo enfadado. La atmósfera de aquella medianoche no era buena. Me parecía algo pequeñoburguesa, de una estrechez palpable, que carecía de la vía libre del trato del hombre con el hombre, de los destellos espirituales, del sentido para la nobleza. La amistad de Husserl tenía, en verdad, calidez, pero sin fuerza ni grandeza. Daba la impresión de que él se sentía cómodo en aquella atmósfera. Por mi parte, estaba bien, un poco distanciado internamente; era indulgente a causa de la libertad, que era la atmósfera natural desde mi hogar y desde Heidelberg. Sólo Heidegger me parecía diferente. Lo visité, me senté a solas con él en su ermita; lo vi en su estudio de Lutero, vi la intensidad de su trabajo, tuve simpatía por su insistente y conciso modo de hablar.

Nunca más estuve de nuevo en Friburgo, no intencionalmente. Invité a Heidegger. Me dio la certeza de que la amistad era el motivo más sutil para acercarse a mí. Debido a sus frecuentes visitas a Heidelberg se desarrolló a lo largo de los años una vivaz relación entre nosotros. A pesar de ello, la relación era en sí algo extraña y aislada. Yo no di a conocer a Heidegger con mis amigos, a excepción de algunos que ocasionalmente venían a casa; él tampoco me presentó a los suyos. Ambos nos comportábamos así sin intención. Pero ello era señal de una falta, como si nosotros, recíprocamente, no hubiésemos querido que el otro tomase parte en el propio mundo sustancial.

Cuando Heidegger estaba de visita con nosotros, ambos procurábamos trabajar. En el transcurso del día nos encontrábamos varias veces para sostener conversaciones. Ya los primeros diálogos entre nosotros me dieron alas. Uno apenas puede representarse la satisfacción que experimenté por ello, por poder hablar seriamente al menos con un individuo dentro del gremio filosófico. ¿Pero en qué yacía la comunidad? Cuando nos sentimos por un corto tiempo en el mismo camino, fue quizás, visto en retrospectiva, un error. Pero eso era también para mí una verdad de la cual hasta hoy no puedo renegar. Clara era la común 
oposición contra los profesores tradicionales de filosofía. Poco clara, pero profundamente conmovedora, la certeza indeterminada de que era necesaria algo así como una revolución en el ámbito de los profesores de filosofía, en el que nos habíamos adentrado con la voluntad de enseñar e influir. Ambos sentíamos como tarea una renovación, no tanto de la filosofía, sino de la complexión en la que entonces se encontraba ella dentro de la Universidad. Común era la conmoción por Kierkegaard.

En nuestros diálogos hablaba yo principalmente. La diferencia de temperamentos era considerable. La inclinación natural de Heidegger al silencio me permitía llegar frecuentemente a excesos del habla.

Ocasionalmente, llegaban estímulos filosóficos. En aquel entonces, a mediados de los años 20, era habitual en Heidelberg que, como antiguo psiquiatra y actual representante de la filosofía, recibiera cartas del rectorado cuyo contenido, sorprendentemente, no era el de cumplir con órdenes. Así, el bedel me trajo una carta proveniente de Frankfurt, de una funcionaria administrativa [y dijo]: "Ahí alguien quiere saber, lo cual es poco menos que nada.” La incorrección ortográfica y gramática con la que había sido escrita la carta, contenía, en un ánimo lleno de angustia, la pregunta por la valía de la ciencia, por si ésta no fuese también nada en realidad. Se trataba de una carta evasora de la angustia, suplicante, presuntamente en una esquizofrenia inicial, manifiestamente pensada en un vistazo de la muerte, pero extraordinaria en las oraciones debido al modo de expresión abstracto. Yo conté esto inmediatamente a Heidegger, quien estaba de visita. Ningún colega hubiera tomado en serio tal carta como él hizo. Nos encontramos ante la evidencia de que en la frase del irónico bedel se veía la ignorancia del mundo.

De igual modo, fallé en algún punto esencial en los primeros años. Cuando nos conocimos acababa de aparecer mi Psicología de las visiones del mundo. Mientras que este libro encontró muchos lectores, no obstante fue rechazado en el gremio; fue descompuesto por Rickert en diversos puntos de vista que eran ajenos a la intención de mi escrito. Por su parte, Heidegger leyó el libro extraordinariamente a conciencia, lo alabó frente a mí como un nuevo comienzo, pero lo puso en duda 
mediante una crítica no pública, igualmente despiadada como todas las otras. Me dio el manuscrito de esa crítica. Me pareció injusta; la leí superficialmente, y no llegó a ser fecunda en mí. Yo andaba caminos distintos a los que él me sugirió. Tampoco tuve el deseo de meterme en esa crítica, de confrontarme con ella, y traer a la claridad en una discusión aquello en lo que consistía la extrañeza del desear, del preguntar, del exigir. Pues en aquel entonces no lo habría podido hacer fácilmente, en tanto que mis esfuerzos filosóficos estaban aún in status nascendi, y se sostenían involuntariamente lejos de aquellos que no los nutrían. Así, presumiblemente, habré decepcionado a Heidegger. Sin embargo, su intercambio de pareceres con el contenido y los puntos de vista de mi libro -en menor medida en la crítica que en el diálogo- fue algo tan positivo que me llegó a estimular.

Me fomenté la exigencia de conceptualidad técnica. El trabajo disciplinado en el pensamiento filosófico lo conocí claramente, a decir verdad, gracias a Lask y Rickert. Sin embargo, eso me parecía un esfuerzo artístico y frecuentemente carente de valor. Desde que había conocido a Husserl, alrededor de 1910, me impuse este trabajo. A partir de la escuela husserliana, en su manera de hablar y comportamiento reconocibles, se me renovó esta impresión en Heidegger en verdad más esencialmente que antes. Mediante Heidegger divisé entre los contemporáneos este algo que, por lo demás, sólo en el pasado ocurría y que es indispensable para poder filosofar. Ciertamente no llegó a darse para mí, en ninguno de los contemporáneos, ni en Heidegger, la norma a la que yo dejara valer para mi trabajo; pero sí se dio algo a lo que me orienté en tanto que forma, para buscar en mi camino y en el diálogo con los antiguos la manera posible, al menos para mí, para aquello que desde la juventud me movió tan profundamente y para lo cual no encontraba ningún lenguaje suficiente y apropiado.

Heidegger me hizo familiar la tradición cristiana del pensamiento, particularmente la católica, aunque no por primera vez; y así también me hizo visible la lozanía extraordinaria de un hombre que con su esencia se sostiene en aquella [tradición] e igualmente la supera. Varias frases, relatos e indicaciones aisladas y dispersas me fueron 
otorgados por él. Recuerdo cómo hablaba de Agustín, de Tomás y de Lutero. Él veía las fuerzas que obraban ahí. Me facilitó literatura valiosa, me llamó la atención sobre ciertos puntos.

Ciertamente en aquel entonces, en los días de nuestras reuniones, y probablemente todavía después, aquello era un ánimo de solidaridad. Dialogábamos con la bella falta de consideración, la cual no impide el opinar de lo que se ve. “¿Cuándo trabaja usted propiamente?” podía él preguntarme, quizás porque veía mis despertares tardíos, que mis sueños estaban tumbados en el sofá. Le desesperaba mi estilo, la falta de disciplina, los soliloquios. Cuando en 1924 yo estudiaba a Schelling, él expresó su menosprecio a partir de la atmósfera de la filosofía científica husserliana: "Sin duda, es un mero literato". No obstante, Heidegger no quería reprenderme, me concedió la libertad de mi camino. No permitíamos que faltaran las recíprocas afirmaciones contenidas y discretas.

Ahora bien, a nuestra inclinación hacia los estímulos recíprocos, a los intereses comunes, no correspondía en absoluto una armonía de la convicción en las estimaciones prácticas, la cual, cuando la hay, nos es evidente, nos soporta y dirige. Aquello permaneció olvidado involuntariamente para la conciencia, aunque emociones de rechazo de lo más sorprendente, que se relacionaban con las declaraciones y opiniones cotidianas, se daban en mí ya desde los primeros años. Desde el comienzo, nuestra relación no tuvo ningún rasgo de entusiasmo. No era una amistad que se fundaba desde la profundidad de la esencia. Debido a circunstancias exteriores, a causa de comportamientos y expresiones, se mezcló algo de distanciamiento. Así, el ánimo entre nosotros no era unívoco; sólo en bellos instantes del diálogo llegaba a ser aquel ánimo algo puro e incondicional, por horas.

Me sucedieron cosas extrañas. En 1923 se publicó un escrito mío La idea de la Universidad. Desde Friburgo se me informó que Heidegger había dicho que ahí estaba la más insignificante de todas las insignificancias actuales. En la siguiente visita le hablé de ello. Le comenté que nuestra relación era de tal manera que requería franqueza recíproca. Que él expresase tal juicio no se lo prohibía en absoluto; pero antes de 
decir del otro algo así, debíamos, no obstante, compartirlo directamente de un modo respetuoso. Heidegger declaró de un modo determinante que él no había dicho semejante cosa. A lo que yo respondí: "Entonces la cosa es inexistente para mí y está acabada". Heidegger estaba consternado por mi reacción: "Nunca he experimentado algo así'; su respuesta no me fue fácilmente comprensible. Que tales habladurías se verificasen a causa de la repetición es un hecho sorprendente. Así, todavía en 1923 se dio en él un cambio: "Jaspers y yo no podemos ser compañeros de lucha". De ahí vino un algo irreal -pero en absoluto rechazable, y más aún, inaprehensible-que turbó el ánimo. Por mi parte, desde 1933 he hablado y juzgado acerca de Heidegger sin hacerlo de su conocimiento.

Desde el inicio, sin considerarlo o siquiera reflexionar acerca de ello, ocasionalmente prescindí de la simple correspondencia para las perogrulladas que, según me parecía, sonaban en tonos falsos. Quizás le sucedió lo mismo frente a mí. Cuando me sentí ligado a él, fue porque vio conmigo, a través de los encubrimientos convencionales, la desgracia, lo más extremo, los límites; y así de inmediato, él se sintió alejado, a causa del modo como lo experimentó. Yo vi su profundidad y difícilmente pude soportar algo diferente, indeterminable. Él parecía un amigo que traicionaba cuando uno estaba ausente, pero que por instantes -que permanecían como algo sin consecuencias- estaba inolvidablemente cerca. Eso me llegó a parecer como si un demonio se deslizara en él; de manera que, desde mi inclinación para lo que en él me exigía esencialmente, no presté atención a los descarrilamientos. En el paso de la década se incrementó la crispación entre el afecto y la extrañeza, entre la admiración por su capacidad y su inexplicable necedad y su rechazar; entre el sentimiento de unanimidad en un fundamento del filosofar y el experimentar, situado ahí mismo, un comportamiento diferente completamente alejado de mí.

En los años posteriores cambió el ánimo de las visitas. Antiguamente venía Heidegger con la voluntad despreocupada, la cual en un primer vistazo era mutua. Después se mostró en sus visitas con un ánimo de indignación y de enemistad. En el paso de uno o dos días desaparecía 
aquella enemistad completamente. Entonces se daba de nuevo lo que me parecía, y todavía hoy me parece, una atmósfera confiable, de un diálogo abierto, compartido y sin prejuicios. Era como si entonces una molestia pasada se evaporara en la convivencia a través de la afinidad, como si una frialdad se derritiera.

La publicación de Ser y tiempo (1927) de Heidegger -sin que en aquél entonces yo lo notara correctamente-no trajo ninguna profundización, sino más bien, una superficialización de nuestra relación. Reaccioné como años antes hacia su crítica a mi Psicología de las visiones del mundo, es decir, no propiamente interesado. Ya en 1922, Heidegger me había leído algunas hojas de un manuscrito de ese entonces. Me era incomprensible. Yo exigía un modo de expresión natural. Heidegger dijo en una ocasión posterior que lo de aquél entonces había sido revisado, que esperaba que a la postre aquello llegara a ser algo. Del contenido del libro publicado en 1927 no tuve conocimiento previo. Ahora veía una obra que, debido a la intensidad del trabajo, a la constructividad del lenguaje técnico, a la precisión de un nuevo uso de las palabras, frecuentemente esclarecedor, había causado impresión inmediatamente. Pero a pesar de la brillantez de su análisis lleno de fuerza, me parecía improductivo para aquello que yo anhelaba filosóficamente. Me alegraba por el mérito del hombre ligado a mí, pero era desalentador adentrarse a leerlo porque el estilo, el contenido, la manera de pensamiento no hacían eco en mí. Tampoco encontré al libro como algo frente a lo cual tuviera que pensar, algo con lo que debiera confrontarme. De ahí no me llegaba, a diferencia de los diálogos con Heidegger, ningún impulso.

Heidegger debía estar decepcionado. No le hice el favor-siendo ya mayor y manteniéndome enteramente en el trabajo exigente de mi filosofar-de una lectura crítica y profunda como él lo hizo de joven, poniendo de relieve su propio pensar, frente a mi Psicología de las visiones del mundo. A eso correspondió, de un modo comprensible, que por su parte no haya puesto ya ningún interés en ninguna de mis publicaciones posteriores. Cuando una relación efectiva entre hombres yace en la obra y en el rendimiento, ahí se da a veces la inclinación a conocer lo 
creado como algo que es más insignificante que la fuerza que acontece en la reciprocidad de la conducta. Es como si uno ya conociese al otro y no necesitara ya leerlo a fondo y completamente. Pero entre Heidegger y yo no era sí. Antes bien, a causa de la obra de ambos, salió a la luz la extrañeza oculta.

Mi ánimo frente al libro y frente a él mismo era la continuación de una ambigüedad o tensión que estaba en germen desde el inicio. En tanto que me había acompañado en los años anteriores una conciencia de comunidad, entonces esperaba ser capaz de percibir en el libro aquello que había en el camino en común. Aunque eso no ocurrió, no le di valor a dicha condición. Yo estaba completamente desconcertado con el ánimo desde el cual hablaba el libro. Una que otra vez aquello alcanzaba expresión en preguntas a Heidegger, como ésta: “¿Qué es lo que le acontece a usted con el pensamiento de este libro? ¿Es el libro una suma de juicios del estado de cosas o la expresión de un impulso de la existencia? ¿Qué debe llegar a efectuarse en el lector a partir del estudio del libro?" Yo bien recuerdo que formulé estas preguntas en la buhardilla de mi casa, pero no que Heidegger hubiera respondido.

En otra ocasión, recordando nuestro juicio acerca de nuestros colegas, frecuentemente dividido, yo mencionaba que era sorprendente que él citara a profesores como si sus problemas no fueran tan distintos a los de ellos. La dedicatoria de su primer libro a Rickert, la del segundo a Husserl enfatizaban una relación con hombres de los cuales él me había hablado con desprecio. Él se comportó con una pertenencia tradicional al mundo, frente a la cual nos habíamos posicionado. A lo cual dijo: "A pesar de ello, ellos son tradicionales en su filosofía fáctica."

Para mí éstas siempre han sido y siguen siendo las preguntas decisivas: ¿hacia cuáles caminos encauza un pensar? ¿Cuáles motivos despierta dicho pensar en el lector? ¿Con vistas a qué dicho pensar lo alienta y lo habilita, y qué dejaría desaparecer y olvidar dicho pensar? Sin aclarármelo, no me di respuesta a lo que el libro de Heidegger significa propiamente. Dejé de lado todo y seguí trabajando en mis investigaciones.

Esta actitud hacia Heidegger con la que suspendía continuamente mi opinión sobre él y su pensar; mi disposición a pasar por alto los 
descarrilamientos; mi indiferencia con la que dejaba pasar y excusaba una crítica efectiva; todo ello no lo pude continuar, en tanto que en 1933 nuestra existencia se transformó radicalmente, y aún hoy exige de cada uno respuesta, a fin de aclarar lo que, y para lo que, cada uno quiere pensar y realizar.

A fines de marzo de 1933, Heidegger nos hizo por última vez una visita prolongada. A pesar de que en las elecciones de marzo el nacionalsocialismo había resultado triunfante, nos comportábamos como antes. Me compró un disco con música sacra gregoriana, el cual escuchamos. Heidegger se marcho más pronto de lo originalmente planeado. "Uno debe alinearse", dijo ante el rápido desenvolvimiento de la realidad nacionalsocialista. Me sorprendí y no pregunté nada.

En mayo estuvo de nuevo, brevemente, con nosotros por última vez, pues sostuvo una conferencia ante los estudiantes y profesores de Heidelberg en la que, ya como rector de la Universidad de Friburgo, fue saludado por el presidente de la sociedad estudiantil de Heidelberg, Scheel, como el camarada Heidegger. Se trataba de una conferencia magistral cuyo contenido era un programa de la renovación nacionalsocialista de la Universidad. Él exigía la total transformación de su esencia espiritual. Los profesores de entonces aún en funciones no eran aptos, en su mayoría, para las nuevas tareas. En diez años llegaría a ser requerida una nueva generación de docentes más apta. Entonces querríamos dejarles nuestros cargos. Hasta entonces se trataba de una situación pasajera. Él guardaba rencor acerca de muchos fenómenos de la realidad universitaria, y también acerca de las altas cuotas. Le reconocieron con un desaforado aplauso los estudiantes y unos pocos profesores. Yo estaba sentado adelante, al margen, con las piernas ampliamente estiradas, las manos en los bolsillos y no me moví.

Más tarde, la conversación no fue franca por mi parte. Le dije que se había esperado que intercediera por nuestra Universidad y su gran tradición. Ninguna respuesta. Hablé acerca de la cuestión judía, acerca del malvado sinsentido de los sabios de Sión, a lo cual él dijo: "Hay, sin embargo, una peligrosa alianza internacional judía." En la mesa dijo, con un tono algo enrabietado, que era una bobada que hubieran tantos 
profesores de filosofía, que sólo se deberían conservar dos o tres. “¿Quiénes, entonces?” pregunté. Ninguna respuesta. “¿Cómo puede gobernar Alemania un hombre tan inculto como Hitler?" "La cultura es completamente indiferente” respondió él, y continuó diciendo: “¡Sólo mire sus maravillosas manos!”.

Así, Heidegger mismo mostró haberse transformado. Ya desde la llegada vino a formársenos un ánimo separador. El nacionalsocialismo se había convertido en una embriaguez del pueblo. Busqué a Heidegger arriba en su cuarto para saludarlo. "Es como en 1914...", comencé a decir, y quise proseguir: "de nuevo esta ilusoria embriaguez de las masas", pero en vistas de la radiante aprobación de Heidegger a lo primero, las palabras se me atoraron en la garganta. Esta ruptura radical me consternó de un modo insólito. Con ningún otro hombre había yo experimentado algo así. Fue aún más irritante en tanto que Heidegger pareció no notarlo en absoluto. Mas, es verdad, él atestiguó la ruptura, dado que desde 1933 nunca más me visitó y tampoco encontré una palabra suya por la destitución de mi puesto. Empero, hacia 1935 escuché que había hablado en una lección de su "amigo Jaspers". Dudo si él ha entendido hoy aquella ruptura.

Yo estaba desconcertado. Heidegger no me había comunicado nada de su inclinación nacionalsocialista antes de 1933. Por mi parte, debí haber hablado con él. En los últimos años antes de 1933 sus visitas se habían vuelto breves. Ahora era demasiado tarde. Fracasé en vista de que Heidegger estaba atrapado por la embriaguez. No le dije que se hallaba en el camino falso. Ya no confiaba en absoluto en su esencia transformada. Yo mismo me sentí bajo la amenaza en vistas de la violencia de la que Heidegger formaba parte y pensé, como en otras ocasiones de mi vida, en la caute de Spinoza.

¿Me había equivocado a causa de todo lo positivo que había existido entre nosotros? ¿Era yo mismo culpable de que no busqué fundar en eso positivo la confrontación radical con él? ¿Era culpa mía haber contribuido a ello antes de 1933, en tanto que no vi correctamente los peligros por haber tomado al nacionalsocialismo como algo completamente inofensivo, a pesar de que Hannah Arendt ya en 1932 me había dicho con suficiente claridad hacia dónde iba? 
En mayo de 1933 Heidegger partió por última vez. No nos hemos visto de nuevo. En los años del nacionalsocialismo mis pensamientos se dirigían frecuentemente a la realidad espiritual, la cual en parte se me personificaba en Heidegger. En contra de mi expectativa, se había convertido en mi enemigo espiritual a causa de su actividad pública como nacionalsocialista. Parecía no notarlo a pesar de que lo atestiguó, pues desde 1933 nunca más me visitó. Su imagen del pasado se me alzaba vivamente ante los ojos y todavía hoy me es inolvidable. No quiero informar lo que desde entonces ha ocurrido entre nosotros epistolarmente, ni acerca del informe de 1945 sobre él, ni de otras cosas. Sólo expongo cómo he pensado de él desde entonces.

Si pienso en Heidegger, veo entonces dos aspectos independientes el uno del otro: la relación real de Heidegger conmigo y su reflejo en lo público. El último tiene efecto en el primero. La repercusión, el eco en lo público del camino de Heidegger, el que de vez en cuando se nos compare a ambos y que nuestros nombres sean frecuentemente nombrados en conjunto, exige en cierto modo dar entrada a nuestro propio encuentro. Quizás la intrusión de aquella publicidad trajo en las recíprocas perspectivas algo equívoco para nosotros mismos, lo cual antes no estaba ahí. Alrededor de 1937, a causa del escrito de Jean Wahl en París, que nos situaba en el mismo espacio de discusión, hemos rechazado simultáneamente aquella comunidad, sin saberlo uno del otro. La opinión pública engendra su fantasma de lo que hoy se toma por existencialismo - lo cual Sartre ha promovido- bajo el que incluye a todos aquellos que hablan de existencia y que tienen una relación con Kierkegaard. La sugestión de tal fantasma es tan grande que los libros de profesores de filosofía hablan acerca de un asunto que creen poder ver como un todo, lo creen ya abarcar con una mirada histórica, y con sus presupuestos creen describir el siglo. Eso me parece absolutamente repugnante, como también a Heidegger aparentemente. Algo extraño se le impone a la propia conciencia de cada uno.

Cuando hablo de Heidegger, debo ignorar esto. Yo tenía una relación personal y filosófica con él. Ésta tiene poco que ver con el debate que compara nuestros escritos y a nosotros mismos. 
Sólo una amistad en la que no hay ningún hermetismo ni reserva oculta alguna; en la que gobierna la fiabilidad de lo conveniente y lo falso en relación con los asuntos sencillos; en la que la lealtad soporta a la palabra, al pensamiento y al comportamiento, se conquista una solidaridad, la cual también resiste ante lo turbio de la opinión pública. Ninguno puede reprochar al otro que tal amistad entre ambos no se haya originado. Esto tiene como resultado el suspenso y la ambigüedad de lo posible.

Que lo que ocurrió con Heidegger en 1933 haya ocurrido suscita nuevas preguntas. Nos habíamos convertido en enemigos no a causa de los libros, sino por medio del comportamiento. El pensamiento filosófico debía llegar a ser comprendido en conexión con la acción de lo pensado.

Ahora se me hace necesaria la pregunta, la cual hasta ahora no me había planteado, de si en el pensar de Heidegger está, en efecto, lo que se puede divisar como enemigo de la verdad. Pues antes me había sentido emparentado con él en los caminos, aun cuando no vinculado en el fundamento. Debía esperar que con la inseparabilidad del pensar y de su praxis del pensamiento, su filosofía también se llegara convertir en opositora a lo que yo intento. Pero eso no fue inequívocamente claro. Antes bien, las preguntas se hicieron palpitantes y permanecieron sin responder: ¿puede haber filosofía que, en tanto obra, sea verdadera, mientras que su función en la facticidad del pensamiento no sea verdadera? ¿Cómo se comporta el pensar respecto de la praxis? ¿Qué es y qué hizo Heidegger propiamente?

En vez de responder a tales preguntas, en lugar de, por consiguiente, intentar una crítica a la filosofía de Heidegger -la cual no pertenece de ningún modo a este lugar- ahora sólo reseño acerca de mi actitud hasta ahora.

Si bien recuerdo, Ser y tiempo de Heidegger fue en dos ocasiones objeto de una breve discusión en mis escritos. Estos puntos son irrelevantes. La ruptura fue demasiado profunda como para que las observaciones críticas sobre la situación, acerca del proyecto abstracto, hubieran sido siquiera relevantes. Lo que se me personificaba era mucho más 
la enemistad desazonante, la cual había percibido a lo largo de mi vida en otras realidades: una enemistad inaprehensible y recusante, la cual ni se sabe como tal, ni se confiesa ni se manifiesta, sino que de un modo sorpresivo se la trata como inexistente. Sin embargo, en la situación concreta interviene una conducta que plantea la elección: o bien uno no llega a aprenderla serenamente, o bien le obliga a permitir la lucha con un ser, al cual en ningún sentido se le siente provenir desde un fundamento idéntico al de sí mismo. No hice frente a Heidegger ninguna de las dos cosas. Lo postergué año con año. Hasta el día de hoy conservo una disposición interna fundada en los instantes de los años veinte. No puedo decir que no donde ya he dicho que sí a un hombre, convencido de la permanencia de la substancia que alguna vez percibí. Pero tampoco puedo pasar por alto, en la amistad humana más convencional, lo esencial; no puedo hacer un trazo de olvido respecto de lo pasado (a menos que fuese posible en una aclaración de común acuerdo la reconciliación desde el fundamento). Aquello no correspondería al rango de Heidegger y sería una traición a lo que existió alguna vez.

Debo impedir que se incurra en un malentendido ocasional. En mis escritos se encuentran muchas caracterizaciones anónimas. Ciertamente están basadas en experiencias de fenómenos contemporáneos, los cuales no nombré cuando la caracterización típica-ideal de la realidad no correspondía a su procedencia, como por ejemplo, al círculo de George, al nacionalsocialismo, al hechizo en la medicina y en la antroposofía. Tales caracterizaciones ocasionalmente se ponen en relación con Heidegger de un modo injusto, pues él ni se apropia de la imagen aristocrática del mundo de George, ni de la bajeza del nacionalsocialismo, ni de la estafa de la doctrina de salvación médica. Sin embargo, de nuevo la pregunta es si en él surte efecto lo que en mis escritos da motivo a la confusión de parte de tales críticos.

Mientras elaboraba mi libro De la verdad, en ocasiones fue de importancia pensar en Heidegger. Esto fue diferente a como sucedió al escribir mi Filosofía en los años veinte. En aquel entonces yo me sentía ligado a él de algún modo, aunque de manera indeterminada, y en absoluto pensando, en el desarrollo de mi filosofar, en el suyo. Ahora se había convertido manifiestamente en el enemigo substancial 
en la realidad del vivir y del obrar, en aquella realidad en la que el filosofar comunicable y practicable es sólo una función. Pero no procedí a una crítica, esencialmente porque me ocupaba de la filosofía, sobretodo en aquél entonces, en la oscuridad del estar excluido del ámbito público.

Por esta razón, sólo pertenece a mis planes, de cuya realización no desisto, intentar una crítica de Heidegger como uno de los representantes de una situación espiritual efectiva entre los contemporáneos. Pero un intento tal requiere la claridad acerca de las posibilidades de una crítica filosófica en general. Esto es uno de los más extraordinarios y apasionantes problemas de la comunicación buscada en la filosofía. Se trata de la pregunta por la confrontación razonable en el filosofar, la cual, me parece, no ha sido planteada hasta hoy de un modo suficientemente claro, ni mucho menos está respondida. Delimito el problema con algunos planteamientos:

1. La pregunta es si en la verdadera filosofía son posibles en realidad una crítica y una polémica esenciales, o si aquí sólo resta una muda aceptación -como lo es el comportamiento hacia un poemala cual bien puede llegar a ser analizada estéticamente, medida críticamente en normas estéticas, interpretada familiarmente; pero no posibilita ninguna confrontación, a menos de que dicha aceptación sustancial sea puesta bajo la escala de si es verdadera y buena, porque ella fomenta el impulso del hombre, o si es falsa y mala porque le quita el impulso y le deja hundirse. Entonces sería válido hacerle estas preguntas a tal filosofía: ¿Despierta la posible existencia a entrar a la realidad? ¿Es tentación para la evasión ante la realidad? ¿Muestra la verdad que se hace obligatoria? ¿Es un pensamiento que permanece sin efecto existencial?

La filosofía no existe como un saber de algo, ni tampoco en la producción de la obra de un pensamiento artístico, sino que en el pensar mismo se produce un comportamiento de la esencia de lo pensado que entra en contacto con lo otro, la trascendencia.

2. En esta esencia del pensar o actuación interna, al igual que en el origen de la comunicación del filosofar, existen poderes efectivos. A tales poderes -los cuales adquieren expresión en la filosofía, en ella se 
reconocen, se revisten y rechazan, se dejan mal juzgar y seducenquisiéramos verlos rectamente. Pero eso no es posible, puesto que a cada paso de nuestro pensamiento nos erguimos en ellos, no fuera de ellos. Nosotros somos nosotros mismos en el servicio a tales poderes, sin que con ello podamos abarcar con la mirada un mundo de los poderes. El "mundo de los poderes" es sólo una metáfora, en tanto que índice hacia aquello sobre lo que es tratado en la auténtica crítica filosófica, a saber, la realidad en obra.

Si dirigimos la mirada a los poderes mismos, entonces ya no miramos más hacia un objeto posible. Antes bien, la exhortación a tal mirada significa solamente buscar en el poder el camino más allá de los objetos hacia el origen de su ser-objeto y su ser-real. Cuando uno cree aprehender ya en la figura de juicios comunicados a los poderes mismos, entonces se trata de un procedimiento asible muy estrecho. Pues los juicios permanecen siempre sólo en el primer plano. Si tomo estos juicios -los que en tanto expresabilidad directa son lo último- como lo realmente último, entonces me oculto lo esencial. Esto depende de cómo llega a hacerse visible, en los juicios expresados, aquello que no es realmente visible. Pero ¿cómo es posible realizar una crítica y cómo es posible efectuar el acuerdo, cuando no se trata acerca de cosas y situaciones concretas y concebibles, sino de la filosofía misma en tanto que lenguaje de los poderes?

3. En el diálogo de los unos con los otros hacemos, por así decirlo, la suposición tácita pero engañosa, de un tema en común -por así decir, del asunto del filosofar- de un mundo de la verdad filosóficamente objetivo, en el cual cada uno de nosotros colabora tanto con lo que es como con lo que piensa. Entonces nos dirigimos a la situación para asirla en forma de proposiciones y razonamientos de una discusión científica. Eso tiene un sentido de hecho, el cual, sin embargo, está limitado a la objetividad racional. Dado que ésta es el medio ineludible de todo lenguaje, tal crítica por tanto, aun siendo superficial, es correcta en relación con el medio a través del cual los poderes profundos se anuncian. Pero ¿cómo es posible señalar e interrogar aquellos poderes, no meramente argumentando, no solamente en discusión de un asunto, 
no simplemente en la concordancia con las formas de la discusión científica? ¿Cómo es posible mostrar las consecuencias, no sólo del pensamiento, sino también de la condición interna, las repercusiones para acompañar afirmativamente en ese camino? ¿Cómo es posible hacer manifiesta la manera en que los pensamientos son la preparación para algo distinto?

En el primer plano la discusión puede llegar a convertirse, inadvertidamente, en engaño. Uno se deja acarrear en el plano de la discusión científica con la presuposición de una filosofía científica común; entonces alcanza mayores nimiedades. Si uno se distrae ante eso, y de dónde proviene, entonces ya se ha aceptado inconscientemente como verdadera la substancia del adversario.

Sin embargo, esta discusión ineludible en el primer plano, llega a ser filosóficamente portentosa solamente cuando aquella discusión profunda de los poderes mismos se asume como su lenguaje.

Ahora bien, la figura de la discusión filosófica pública es particular. En muchos casos, cuando un crítico está manifiestamente ligado a su adversario -y tanto más cuando éste es un filósofo productivo- a causa de ello se deja colocar inadvertidamente en la vía de pensamiento del adversario. Así ha ocurrido frecuentemente en la discusión crítica de Hegel entre hegelianos y antihegelianos. Con todo lo interesante que puede ser histórico-espiritualmente, dicha crítica es inesencial porque no tiene ningún adversario en verdad, sino que cultiva el mismo camino con el adversario aparente, en atadura a él, capturado en una manera de pensar, a disgusto e inconsciente de la ligadura. En tal caso, en una discusión aparente, junto a los más vigorosos rechazos, la discusión esencial no ha comenzado en absoluto. El prisionero, esforzándose en cierto modo, quiere liberarse de la atadura, pero inútilmente.

4. Lo profundo, el genuino poder filosófico, ese algo que se experimenta o no se experimenta, y que no se deja imponer ningún conocimiento del entendimiento; eso que, en la disposición espiritual es lo propiamente efectivo y que como tal dirige la palabra; frente a ello está inmediatamente la pregunta: ¿está en realidad ahí o no? Esto significa: ¿es algo o se trata de un hechizo? Y a continuación está la segunda pregunta: ¿qué clase de poder o poderes imponen validez? No 
se puede alcanzar respuesta definitiva a eso. Quizás se pueda caracterizar un poder, se pueda rozarlo, rechazándolo o apropiándolo. La tarea consiste, en cierto modo, en poder acercarse a ello cara a cara, no incluirlo bajo un concepto general o un concepto-tipo.

Una confrontación de esta clase sólo tiene sentido si interroga desde y en la raíz, y si busca los pensamientos apropiados para los motivos originarios procedentes de ahí. Pues la exhibición de las circunstancias del adversario, al ser recordadas, enseña a ver algo que, no en sí sino como señal, síntoma o símbolo, tiene el significado de una voluntad-esencial filosófica.

Lo anterior es imposible para poderse efectuar como un conocimiento universal. Como quiera que uno gire alrededor de lo buscado y lo exponga, cuando es pensado críticamente, se da nuevamente la misma tendencia proveniente del propio origen - la cual se muestra en las formas de pensamiento- a que uno esté sujeto, una vez más, a la reflexión y a la pregunta de lo mismo.

En la vida filosóficamente pensada se muestra una lucha de los poderes. Pero no se debe a olvidar que nadie en este mundo abarca con la mirada de la misma manera al, por así llamarlo, organismo de los poderes originarios de la verdad, beligerantes entre sí. Y nadie reconoce, en un saber definitivo y general, su gran diferencia respecto de los poderes autodestructores de la no-verdad y del mal para la existencia empírica, para la existencia posible, para la razón y para la realidad. La totalidad es una metáfora para aquello donde estamos parados y desde lo cual de ninguna manera podemos rebasar para abarcarla efectivamente desde fuera con la mirada.

5. Cuando se dirige la mirada hacia los poderes originarios, entonces se trata acerca de algo que está encarnado, tanto en el obrar de lo pensado como en el contenido de sus pensamientos. Lo que se busca preguntando de este modo es lo universal en lo más personal.

Por consiguiente, cuando se trata de una crítica, el propio hombre viviente, al filosofar en su facticidad, es traído hacia dentro de sí. Eso es lo ineludible, a partir de que el contenido de la filosofía no puede llegar a ser tratado más al modo de algo investigable científicamente, 
mediante hallazgos y pruebas en el progreso de lo cada vez más reconocible a lo largo de las épocas. Sin embargo, con ello existe, a la vez, una conciencia del límite y una medida de la crítica, la cual, estrictamente, no puede llegar a ser inculcada de un modo suficiente, ni se puede decidir llegar a retenerla suficientemente: así como apenas puede llegar a ser observable y conocida para algún hombre en su totalidad, tampoco llega a serlo para el pensador filosófico con su trabajo. Uno puede ahondar, pero no abarcar con la mirada. Uno puede poner en cuestión, pero no señalar algo así como un balance.

Con el intento imperioso de la crítica filosófica en los orígenes, donde tal crítica parece llegar al límite de lo casi forzosamente persuasivo -el cual, sin embargo, nunca puede alcanzar- se llega a dar una posible objeción, la cual anula de golpe toda búsqueda crítica en su conjunto. Dicha objeción vale propiamente sólo frente a los contemporáneos y sólo potencialmente frente a los muertos. Dicha objeción reza: es imposible exigir del adversario que tenga que saltar sobre su propia sombra, exigir una inspección que le obligue a entumecer su productividad propia. Goethe dijo en una ocasión que no se debe admitir lo que está en contra de las condiciones de la propia existencia. Frente a tal objeción habría que decir: esa es la grandeza del filosofar, que aquí y sólo aquí vale tal objeción. Pues el filosofar anhela cada juicio posible. Él es espíritu cuya productividad sólo es una herramienta, y no un fin en sí mismo. Él llega a experimentar que emplea aún mejor esta herramienta cada vez que es conmovido rotundamente por el impulso del perseverar. Por ello, el filosofar busca precisamente la crítica más extrema.

Al dirigirse al pensar de Heidegger con tales preguntas, las cuales aquí sólo son esbozadas en una forma general, no sería ninguna casualidad contentarse con argumentos y volcarse hacia el mero entendimiento. Antes bien, habría que intentar una crítica al contemporáneo, en analogía a como es nuestro constante comportamiento frente a los filósofos anteriores, [a saber] sólo atención unilateral. En esta autobiografía filosófica ni siquiera he comenzado esta crítica. Aquí sólo he aludido a recuerdos de décadas, los cuales no están afectados por la obra 
de Heidegger, sino por aquello que entre él y yo sucedió, se pensó y se hizo. Quizás ahí dentro yace algo que, con una crítica madura, podría llegar a ser esencial en una confrontación con la obra. La crítica filosófica, que hasta ahora sólo está puesta en marcha por mi parte de un modo oculto, en notas ocasionales, si resultara bien, podría llegar a tener sentido cuando el compañero responda. Mientras vivamos, siguen existiendo posibilidades presentidas. Lo que había desde 1933 y lo que hay al día de hoy entre Heidegger y yo me parece estar abierto. No puedo darlo por terminado. 